\title{
Intracranial Venous Sinus Stenting Improves Headaches and Cognitive Dysfunction Associated with Ehlers-Danlos Syndrome Type III
}

\author{
Mohanarao Patibandla' ${ }^{2}$, Ryan J Jafrani ${ }^{1}$, Robert Maurer*1, Thomas J Buell ${ }^{2}$, Daniel MS Raper ${ }^{2}$, \\ Ching Jen Chen ${ }^{2}$, Dale Ding ${ }^{3}$, Robert M Starke ${ }^{4}$ and Kenneth Liu ${ }^{1}$ \\ ${ }^{1}$ Department of Neurosurgery, Penn State Hershey Medical Center, United States \\ ${ }^{2}$ Department of Neurosurgery, University of Virginia Health System, United States
}

${ }^{3}$ Department of Neurosurgery, University of Louisville School of Medicine, United States

${ }^{4}$ Department Neurosurgery and Radiology, University of Miami, United States

*Corresponding author: Robert Maurer, Department of Neurosurgery, Penn State Hershey Medical Center, United States

\section{ARTICLE INFO}

Received: 幽 March 09, 2020

Published: 慧 March 13, 2020

Citation: Mohanarao P, Ryan JJ, Robert M, Thomas JB, Daniel MSR, et al., Intracranial Venous Sinus Stenting Improves Headaches and Cognitive Dysfunction Associated with Ehlers-Danlos Syndrome Type III. Biomed J Sci \& Tech Res 26(4)-2020. BJSTR. MS.ID.004374.

Keywords: Ehlers-Danlos Syndrome; Intracranial Venous Stent; Intracranial Venous Sinus Stenosis; Headaches; Cerebral Angiography; Neurosurgery

Abbreviations: EDS: Ehlers-Danlos Syndrome; HT: Hypermobility Type; VSS: Venous Sinus Stenting; CNS: Central Nervous Systems; IIH: Idiopathic Intracranial Hypertension; BMI: Body Mass Index; ACT: Activated Clotting Time; CT: Computerized Tomography; CTV: Computed Tomography Venography; SAS: Stent-Adjacent Stenosis; TS: Transverse Sinus; SS: Sigmoid Sinus

\section{ABSTRACT}

The most common subtype of Ehlers-Danlos syndrome (EDS) is type III, or hypermobility type (EDS-HT). A large proportion of this population suffers from debilitating headaches and cognitive dysfunction of unclear etiology. We hypothesize that a subset of these patients has underlying cerebral venous sinus outflow abnormalities contributing to these symptoms, and that outflow optimization with endovascular stenting may ameliorate these symptoms. In this study, consecutive EDS-HT patients presenting with headache and cognitive dysfunction were evaluated with intracranial venous manometry. Patients who were found to have a significant venous sinus pressure gradient and were treated with venous sinus stenting (VSS). A database of these cases was prospectively maintained and retrospectively reviewed for this study. The study cohort comprised 130 patients with EDS-HT, including 74 who underwent VSS. Technical success with resolution of the pressure gradient was achieved in $100 \%$, with a $4 \%$ rate of significant procedural complications. Headaches and cognitive dysfunction significantly improved or completely resolved in $77 \%$ of patients, were unchanged in $11 \%$, and worsened in $4 \% .7 \%$ were lost to follow-up. Our results support the hypothesis that intracranial venous outflow abnormalities contribute to the underlying etiology of headache and cognitive symptoms in some patients with EDS-HT. Diagnostic venography with venous manometry is necessary to identify the population of EDS-HT patients who may benefit from VSS. VSS appears to have a favorable risk to benefit profile, and it may be considered as a minimally invasive treatment option for appropriately selected patients with this disorder.

\section{Highlights}

a) Headaches \& cognitive complaints are common in the Ehlers-Danlos population.

b) This seems to be due to Intracranial venous outflow abnormalities in some patients.

c) In this study, 130 patients were evaluated with DSA \& intracranial venous manometry.

d) 74 of 130 were treated with venous sinus stenting, with excellent clinical outcomes. 


\section{Introduction}

Ehlers-Danlos syndrome (EDS) is a heterogeneous group of heritable connective tissue disorders characterized by joint hypermobility, tissue fragility, and skin extensibility [1]. It is estimated to have a prevalence of up to 1 to $3 \%$ of the general population [2]. Multiple subtypes have been characterized, the most common being Type III or hypermobility type (EDS-HT). In EDS-HT, the causative genetic mutation or mutations are not well delineated. Therefore, the diagnosis of EDS-HT is based on clinical assessment and family history, and it is characterized by musculoskeletal and cutaneous manifestations, and frequently affects other systems including cardiac, immune, gastrointestinal, autonomic nervous and central nervous systems (CNS). CNS and spine manifestations associated with EDS-HT include headaches, Chiari I malformation, craniocervical instability, basilar invagination, spondylotic cervical spine disorders, tethered cord, idiopathic intracranial hypertension (IIH), chronic fatigue, and cognitive slowing [1,3]. The abovereported associations have been poorly quantified in the literature to date, and as such, this syndrome requires further and more definitive characterization.

Cognitive dysfunction, described as "brain fog", chronic fatigue, or as subsyndromal delirium (DSM-IV-TR) are common, and can be incapacitating. The neuropathophysiological basis for these symptoms in EDS patients is unclear. Debilitating pressure headaches are another common complaint in patients with EDS-HT. Headaches in these patients are multifactorial, but in select patients, we hypothesize that headaches are due to venous hypertension, which may be amenable to neurosurgical or neuroendovascular intervention. Recent studies have demonstrated that in the general population without EDS, venous hypertension, in both IIH and non-IIH patients, is a cause of headaches that may be amenable to treatment with endovascular stenting of the dural venous sinuses, albeit with variable results [4-35]. Borderline venous hypertension, presenting as chronic fatigue syndrome, has also been treated with venous sinus stenting (VSS), but the available data for this application is very limited [4]. In this retrospective cohort study, we evaluate the outcomes of VSS for the treatment of EDS-HT.

\section{Materials and Methods}

130 consecutive EDS-HT patients who presented with headache and chronic fatigue between the years of 2015 and 2016 were evaluated with diagnostic angiography and intracranial venous manometry. 74 of the 130 evaluated patients were treated with VSS. A database of EDS-HT patients who underwent VSS was prospectively maintained and retrospectively reviewed.

\section{Patient Selection and Characteristics}

The inclusion criteria of the study were as follows:

(1) A diagnosis of EDS type III (EDS-HT),
(2) Presentation with cognitive dysfunction and/or severe headache, and

(3) Angiographic analysis, including intracranial venous manometry.

The database included clinical and demographic features (including the presence of other neurological conditions implicated with EDS in the literature), prior treatments, imaging data, procedural details, and clinical outcomes. Baseline variables included gender, age, clinical features at presentation, body mass index (BMI), location of venous sinus stenosis, maximum mean venous pressure (mMVP), and trans-stenosis venous pressure gradient. Outcomes data included post-stenting mMVP and transstenosis pressure gradient, as well as change in preoperative headache and neurological symptoms, as evaluated by clinic visits and telephone interviews. Headache, cognitive dysfunction, and other symptoms were assessed by structured interviews and categorized as follows:

1) Resolved or significantly improved (residual symptoms not requiring continued intervention or $>50 \%$ improvement).

2) No change.

3) Worsened (worse symptoms than prior to VSS procedure); and

4) Different (change of symptom characteristics or new symptoms compared to their pre-VSS status).

\section{Diagnostic Angiography, Venography, and Manometry}

Cerebral angiography, venography, and venous manometry was performed under minimal conscious sedation. Cerebral angiography from a transfemoral arterial approach was performed in all cases to exclude a vascular malformation or arteriovenous fistula as an alternative source of increased intracranial pressure. Cerebral venography and manometry, from a transfemoral venous approach, were performed in the following manner: a guide catheter was positioned into the distal internal jugular vein proximal to the jugular bulb. Next, the superior sagittal sinus was selected with a Renegade Hi-Flo (Boston Scientific, Natick, MA) or Headway 27 microcatheter (Micro Vention, Aliso Viejo, CA) over a microguidewire. After cerebral venography was performed, a pressure transducer was attached and zeroed. Pressure measurements were documented within the distal, middle, and proximal segments of the superior sagittal sinus, dominant transverse sinus, sigmoid sinus, jugular bulb, and distal internal jugular vein. In some cases, venous pressures in the straight sinus were also measured and recorded.

\section{Venous Sinus Stenting Procedure}

Patients with a significant pressure gradient across an angiographically demonstrated venous sinus stenosis were offered 
VSS. Patients with no evidence of a significant venous pressure gradient were not offered VSS, regardless of the presence of angiographic venous sinus stenosis. Before VSS, patients were loaded with antiplatelet agents: aspirin $650 \mathrm{mg}$ and clopidogrel 600 mg. Aspirin and P2Y12 VerifyNow ${ }^{\circledR}$ Response Assays (Accumetrics, Latham, NY) were performed to evaluate the hematological effect of the antiplatelet agents. Additional aspirin and clopidogrel or alternative antiplatelet agents (i.e., for non-responders to one or both medications) were administered as necessary. VSS procedures were performed under general endotracheal anesthesia. Transfemoral venous access was obtained in standard fashion.

Intravenous heparin was loaded at a dose of 100 units $/ \mathrm{kg}$ at the outset of the procedure and additional heparin was administered as necessary to achieve and maintain an activated clotting time (ACT) of 250-300 seconds. After venous access was obtained, a support catheter was placed into the internal jugular vein or sigmoid sinus. Pressure assessments were then measured again across the venous sinus stenosis, and VSS was carried out using an appropriately sized device. Stents utilized included the Precise stent (Cordis, Bridgewater, NJ), Protégé stent (Covidien, Mansfield, MA), and Wallstent (Boston Scientific, Natick, MA). After angiographic verification of suitable stent placement, pressure levels were repeated and recorded. Post-stenting arteriograms were obtained to assess changes in hemispheric venous drainage patterns. Dual antiplatelet drugs were continued for a month following stent placement, followed by aspirin monotherapy for six months.

\section{Clinical and Radiographic Follow-Up}

Patents were seen in neurosurgery clinic at three months after VSS, and then annually thereafter. Radiographic follow-up included cerebral angiography, venography, and venous manometry at 3 and 12 months after VSS to assess venous pressure gradient across the stent and patency of stent. Patients were followed with computerized tomography (CT) angiography and venography, with repeat cerebral angiography, venography, and venous manometry as needed for new or worsening neurological symptoms. Secondary venous sinus stenosis was defined as stenosis adjacent to or within a stent at follow-up angiography

\section{Statistical Analysis}

Data are presented as median, mean and range for continuous variables, and as the frequency for categorical variables. Wilcoxson's matched pairs signed rank test, assuming the non-Gaussian distribution of variables, was performed to compare continuous variables including maximum mMVP and trans-stenosis pressure gradient. Logistic regression analysis was performed to analyze factors contributing to the successful clinical outcome. P-values $<0.05$ were considered statistically significant. All statistical analyses were carried out utilizing MedCalc for Windows, version 15.0 (MedCalc Software, Ostend, Belgium)

\section{Results}

\section{Patient Characteristics}

The study cohort comprised 130 patients with EDS-HT who underwent angiographic evaluation. Table 1 summarizes the patient characteristics of the study cohort. The cohort was primarily female, consisting of 118 (90.8\%) female patients and 12 (9.2\%) male patients with a mean age of 30.9 (range 10-57) years and BMI of $27 \pm 7.5$ (range $13-42.3$ ) $\mathrm{kg} / \mathrm{m}^{2}$. The most common presenting symptoms were headache, cognitive dysfunction (i.e., "brain fog"), pulsatile tinnitus, and transient visual obscurations in 130 (100\%), 83 (63.8\%), 68 (52.3\%), and 54 (41.5\%), respectively.

Table 1: Demographics, Clinical characteristics and associations of hEDS population.

\begin{tabular}{|c|c|}
\hline \multicolumn{2}{|c|}{$\begin{array}{l}\text { Demographics, Clinical Characteristics and Associations of hEDS } \\
\text { Population }\end{array}$} \\
\hline $\begin{array}{l}\text { Total hEDS patients evaluated with } \\
\text { angiograms }\end{array}$ & 130 \\
\hline Total patients underwent stenting & 74 \\
\hline Total number of stent procedures & 90 \\
\hline Female : Male & $118: 12$ \\
\hline BMI (Mean \pm SD) Kg/m² (range) & $27 \pm 7.5(13-42.29)$ \\
\hline Age in years (Mean \pm SD) (range) & $30.9 \pm 12.3(10-57)$ \\
\hline Obesity (BMI >30.0) (\%) & $89(68.4)$ \\
\hline Chiari type $1(\%)$ & $79(60.8)$ \\
\hline Syrinx $(\%)$ & $11(8.5)$ \\
\hline Dysautonomia (\%) & $46(35.4)$ \\
\hline POTS (\%) & $73(56.2)$ \\
\hline Migraines (\%) & $22(17)$ \\
\hline Tethered Cord (\%) & $47(36.2)$ \\
\hline $\begin{array}{l}\text { Idiopathic intracranial } \\
\text { hypertension }(\%)\end{array}$ & 38 (29.3) \\
\hline Scoliosis (\%) & $12(9.2)$ \\
\hline Shunt (\%) & $23(17.7)$ \\
\hline Cranio cervical instability (\%) & $66(50.8)$ \\
\hline Previous fusions (\%) & $61(47)$ \\
\hline Headache $(\%)$ & $130(100)$ \\
\hline Tinnitus (\%) & $68(52.3)$ \\
\hline Brain fog $(\%)$ & $83(63.8)$ \\
\hline Visual symptoms (\%) & $54(41.5)$ \\
\hline
\end{tabular}

\section{Previous Treatments}

Of the 38 patients who carried a previous diagnosis of IIH, $23(60.5 \%)$ had previously undergone ventriculoperitoneal or lumboperitoneal shunt placement. Most of these patients had failed acetazolamide due to intolerance of side effects or lack of therapeutic benefit. All patients previously diagnosed with Chiari 
type I malformation had previously undergone posterior fossa decompressive surgery. 61 of the 66 patients diagnosed with craniocervical instability had previously undergone occipitocervical fusion $(92 \%)$.

\section{Treatment Characteristics and Outcomes}

Of the 130 patients who underwent catheter angiography, only one suffered a complication from the procedure (dissection of left vertebral artery) that was felt to be purely technical and avoidable. Table 2 summarizes the imaging findings of the study cohort. A primary venous pressure gradient was found in 74 (57\%) patients and structural venous stenosis in 57 (43.8\%) patients at initial angiography, venography, and venous manometry. Previous magnetic resonance venography (MRV) and computed tomography venography (CTV) demonstrated structural venous abnormality in only $29(22.3 \%)$ patients. Table 3 summarizes imaging characteristics of the 74 EDS-HT patients who underwent VSS. The 74 patients underwent a total of 90 VSS procedures, including 16 secondary VSS procedures in 10 patients for stent-adjacent stenosis (SAS). We noted structural stenosis on angiography, CTV, or MRV in 46 (62.2\%), $13(17.6 \%)$ and 11 (14.9\%) patients in the stented group, respectively. Stent placement was on the right in 49 (54.4\%) patients and on the left in 39 (43.3\%), with one patient undergoing bilateral $(2.3 \%)$ VSS procedures.

Table 2: Imaging in total 130 hEDS group (angiogram and Venograms findings).

\begin{tabular}{|c|c|}
\hline \multicolumn{2}{|c|}{$\begin{array}{c}\text { Imaging in total 130 hEDS Group } \\
\text { (Angiogram and Venograms Findings) }\end{array}$} \\
\hline CTV & $14(10.8)$ \\
\hline MRV & $15(11.5)$ \\
\hline Angiographic anatomical stenosis & $57(43.8)$ \\
\hline Bilateral angiographic structural \\
stenosis & $12(9.2)$ \\
\hline IJV structural stenosis & 17 \\
\hline TS and SS structural stenosis & 31 \\
\hline SSS structural stenosis & 15 \\
\hline Others (straight sinus) & $15 \pm 7.1(3-41)$ \\
\hline Conscious sedation MVP (Mean \\
\pm SD)
\end{tabular}

CTV: Computerized Tomogram Venogram; MRV: Magnetic Resonance Venogram; SD: Standard Deviation; IJV: Internal Jugular Vein; TS: Transverse Sinus; SS: Sigmoid Sinus; SSS: Superior Sagittal Sinus; MVP: Maximum Venous Pressure; GA: General Anesthesia.
Table 3: Imaging characteristics in stented group (n-74)(primary and secondary stenting).

\begin{tabular}{|c|c|}
\hline \multicolumn{2}{|c|}{$\begin{array}{l}\text { Imaging Characteristics in Stented Group (n-74) (Primary and } \\
\text { Secondary Stenting) }\end{array}$} \\
\hline $\begin{array}{l}\text { Total patients evaluated with } \\
\text { angiograms }\end{array}$ & 130 \\
\hline Total patients underwent stent & 74 \\
\hline Total number of stent procedures & 90 \\
\hline Total number of stents & 112 \\
\hline CTV stenosis (\%) & $13(17.6)$ \\
\hline MRV stenosis (\%) & $11(14.9)$ \\
\hline $\begin{array}{c}\text { Angiographic structural stenosis } \\
(\%)\end{array}$ & $46(62.2)$ \\
\hline $\begin{array}{l}\text { Bilateral angiographic structural } \\
\text { stenosis (\%) }\end{array}$ & $11(14.9)$ \\
\hline IJV structural stenosis (\%) & $12(16.2)$ \\
\hline TS and SS structural stenosis (\%) & $31(41.9)$ \\
\hline SSS structural stenosis (\%) & $4(5.4)$ \\
\hline $\begin{array}{l}\text { Straight sinus structural stenosis } \\
\qquad(\%)\end{array}$ & $1(1.4)$ \\
\hline $\begin{array}{l}\text { Conscious sedation MVP (Mean } \pm \\
\text { SD) }(\%)\end{array}$ & $17.4 \pm 8.4(3-41)$ \\
\hline $\begin{array}{l}\text { Conscious sedation Pressure } \\
\text { gradient (Mean } \pm \text { SD) }(\%)\end{array}$ & $6.9 \pm 4.5(0-26)$ \\
\hline MVP under GA (\%) & $17.5 \pm 6.7(4-35)$ \\
\hline Pressure gradient under GA (\%) & $5.8 \pm 3(0-13)$ \\
\hline Pre and post stent angioplasty (\%) & $1(1.4)$ \\
\hline Bilateral stent (\%) & $1(2.2)$ \\
\hline Right (\%) & $49(54.4)$ \\
\hline Left $(\%)$ & $39(43.3)$ \\
\hline TS and SS (\%) & $43(47.8)$ \\
\hline SSS to TS or SS (\%) & $16(17.8)$ \\
\hline IJV (\%) & $26(28.9)$ \\
\hline SSS $(\%)$ & $4(4.4)$ \\
\hline Straight sinus to TS (\%) & $1(1.1)$ \\
\hline Post stent gradient normalized & $100 \%$ \\
\hline Gradient more than $10(\%)$ & $10(13.5)$ \\
\hline
\end{tabular}

CTV: Computerized Tomogram Venogram; MRV: Magnetic Resonance Venogram; SD: Standard Deviation; IJV: Internal Jugular Vein; TS: Transverse Sinus; SS: Sigmoid Sinus; SSS: Superior Sagittal Sinus; MVP: Maximum Venous Pressure; GA: General Anesthesia.

The most common stent construct involved the transverse and sigmoid sinuses $(\mathrm{N}=43,47.8 \%)$. The second most common site was the internal jugular vein $(\mathrm{N}=26,28.9 \%)$. In 16 (17.8\%) patients, the stent construct spanned from the superior sagittal sinus (SSS) to the transverse sinus (TS) or sigmoid sinus (SS). Four (4.4\%) patients underwent isolated stenting of the SSS alone. A total of 112 stents were used, including a single stent in 72 procedures (80\%), two stents in 14 procedures (15.5\%), and three stents in 4 procedures $(4.5 \%)$. The mean time interval from initial VSS to 
restenosis and repeat VSS was nine months (10 patients with 16 stenting procedures). While secondary stenosis was seen at followup angiography in 37 of the 112 deployed stents (24 with in-stent stenosis, 11 with SAS, and 2 with waist deformity), only 10 patients had increased venous pressure gradients. These 10 patients underwent a total of 16 re-stenting procedures. The mMVP in the intracranial venous system of the 74 patients who underwent VSS was $17.5 \pm 6.7$ (range 4-35) $\mathrm{mmHg}$ prior to stent deployment. The mMVP decreased to $14 \pm 6.3$ (range 1-40) $\mathrm{mm} \mathrm{Hg}$ after stenting, and this difference between the pre- and post-VSS mMVPs was statistically significant $(\mathrm{p}=0.0013)$. The trans-stenosis venous pressure gradient decreased from $5.8 \pm 3 \mathrm{mmHg}$ to $1.0 \pm 1.5 \mathrm{mmHg}$ after stenting $(\mathrm{p}<0.0001)$.

\section{Clinical Outcomes and Complications}

Table 4: Outcomes of stented group.

\begin{tabular}{|c|c|}
\hline \multicolumn{2}{|c|}{ Clinical } \\
\hline $\begin{array}{l}\text { Clinical Follow-up (months) } \\
\text { (mean } \pm \text { SD) (range) }\end{array}$ & $4 \pm 4(0-51)$ \\
\hline Improved (\%) & $57(77)$ \\
\hline Deteriorated (\%) & $3(4)$ \\
\hline No change (\%) & $8(10.8)$ \\
\hline Not available (\%) & $5(6.8)$ \\
\hline Death (\%) & $1(1.4)$ \\
\hline Re stenting (\%) & $\begin{array}{c}10 \text { (13.5) (16 stent procedures } \\
(17.8 \%)\end{array}$ \\
\hline $\begin{array}{l}\text { VP or LP Shunt after high volume LP } \\
\qquad(\%)\end{array}$ & 5 \\
\hline Mean time for re stenting months (\%) & 9 \\
\hline \multicolumn{2}{|c|}{ Radiological } \\
\hline MVP after stent (range) & $14 \pm 6.3(1-40)$ \\
\hline $\begin{array}{l}\text { Pressure gradient following stent } \\
\text { (range) }\end{array}$ & $0.96 \pm 1.5$ ( -2 to 9$)$ \\
\hline \multicolumn{2}{|c|}{ Complications } \\
\hline $\begin{array}{l}\text { Vessel dissection (common femoral } \\
\text { artery) (\%) }\end{array}$ & $1(1.1)$ \\
\hline Micro catheter tip break (\%) & $1(1.1)$ \\
\hline Acute SDH (\%) & $2(2.7)$ \\
\hline Waist constriction of stent (\%) & $2(2.22)$ \\
\hline Stent adjacent stenosis (\%) & $11(12.2)$ \\
\hline Stent stenosis (\%) & $24(26.6)$ \\
\hline Death $(\%)$ & $1(1.4)$ \\
\hline
\end{tabular}

SDH: Subdural Hematoma; SAH: Subarachnoid Hemorrhage; VP: Ventriculo Peritoneal; LP: Lumbo Peritoneal.

Table 4 summarizes the clinical outcomes and complications of the EDS-HT patients who underwent VSS. 57 (77\%) patients reported that their symptoms resolved or significantly improved, $8(10.8 \%)$ reported no change in symptoms, and $3(4 \%)$ reported worsened symptoms. The mean follow-up duration was $4 \pm 4$ (range $0-51$ ) months, including $7 \%$ of treated patients who were lost to follow up. There were four periprocedural complications in the patients who underwent VSS. One patient had a common femoral artery dissection which required surgical exploration (1.1\%). Two patients $(2.7 \%)$ developed an acute subdural hematoma postoperatively. Of these two patients, one had acute neurological deterioration leading to decompressive craniectomy and eventual death $(1.1 \%)$. The second patient had a small subdural hematoma and subarachnoid hemorrhage due to microcatheter perforation of the venous sinus wall. Serial imaging was stable, and the patient was managed conservatively with a good outcome. In one case, the microcatheter tip fractured without any identifiable clinical consequences. No complications were encountered during the diagnostic angiograms (Table 2).

\section{Discussion}

EDS-HT is a heritable connective tissue disorder characterized by joint hypermobility, skin extensibility, and tissue fragility [1]. It is recognized as a multisystem disorder affecting the cardiac, immune, gastrointestinal, and nervous systems. Headache is one of the most common complaints in EDS-HT patients. The etiology of headaches in these patients is heterogenous, multifactorial, and associated with migraines, Chiari malformation type I, craniocervical instability, cervical spine disorders, and IIH [1,3]. Our study suggests that a subset of EDS-HT patients may experience headaches related to abnormal cerebral venous outflow, and that this may be amenable to stenting of the intracranial venous sinuses.

\section{Neurological Associations in EDS-HT}

Chiari malformation type I, IIH, migraines, autonomic disturbances, craniocervical instability, and tethered cord have all been reported in the literature as comorbid conditions in patients with EDS-HT. However, the frequency of these associations remains poorly quantified. In our cohort of 130 patients with EDS-HT, Chiari malformation type I was seen in 79 (60.8\%), syrinx in 11 (8.5\%), POTS in $73(56.2 \%)$ and other dysautonomia diagnoses in 46 (35.4\%), migraine in 22 (17\%), IIH in 38 (29.3\%), tethered cord in $47(36.2 \%)$, craniocervical instability in $66(50.8 \%)$, and scoliosis in $12(9.2 \%)$.

\section{Headache and Cognitive Symptoms}

EDS-HT patients with significant headache symptoms present a therapeutic challenge. Headaches in these patients are complex, with multiple etiological factors and associations. Proposed mechanisms include CSF or venous flow- dysfunction related to ligamentous complex instability. Chiari malformation type $\mathrm{I}$ is a comorbid condition to EDS-HT and may be further complicated by craniocervical instability or basilar invagination. In addition to headaches, EDS-HT patients commonly present with similar cognitive complaints, fitting the diagnosis of mild dementia, or more commonly self-reported as "brain fog." Brain fog is characterized as a disturbance of consciousness, the significant clinical features of which are abnormalities in attention, thought process, comprehension, and language. In severe cases, more overt neurologic issues can manifest, including hemiparesis, paraparesis or quadriparesis. 
VSS has been previously shown to reliably lower ICP and improve headaches in certain patients [7,20,29,34]. Additionally, we have noticed that chronic fatigue and cognitive slowing that is common amongst this patient population often improves dramatically after VSS. While the mechanism for this is unknown, we hypothesize that these patients have a dysfunctional glymphatic system, and that improving venous outflow may help to restore its function. The glymphatic system is a theorized process that clears extraneuronal debris. This pathway concludes with clearance of parenchymal interstitial fluid, including metabolic waste products, into large caliber draining veins. The continuous flow of fluid through the pathway is believed to be critical to solute clearance. It is plausible that by improving venous outflow, this process is improved, thereby resulting in symptomatic improvement in patients with EDS-HT.

\section{Treatment Options}

EDS-HT patients tend to be complex, with a history of numerous invasive procedures for conditions related to headaches, as evidenced by the large percentage of patients in our cohort with a history of foramen magnum decompression for Chiari malformation type I, occipitocervical fusion for craniocervical instability, and/or CSF shunt placement for IIH. Each of these surgeries carries the potential for significant morbidity, and in our cohort, were largely ineffective in relieving headaches. Recent literature in the setting of headache [4-35] and fatigue [4] supports a causal relationship between these symptoms and venous outflow obstruction in some patients. Our experience suggests that this relationship may apply to a proportion of EDS-HT patients. In this difficult population, who often undergo invasive procedures for headaches, our aim is to improve headaches and quality of life using a minimally invasive endovascular procedure with a durable effect.

\section{Cerebral angiogram, Venograms, and Venous Stenting}

We analyzed our cohort of 130 EDS-HT patients who underwent angiography to evaluate venous outflow obstruction. Of the patients in our cohort undergoing catheter angiography, only one suffered an asymptomatic complication from the angiographic procedure that was felt to be technical in nature and therefore avoidable. This complication rate is similar to that seen in the general population undergoing catheter angiography. This contradicts the conventional wisdom among neurointerventionalists performing these procedures, which dictates that patients with EDS are at higher risk of procedural complications from angiography. A physiologically significant trans-stenosis venous pressure gradient was identified in 57\%, and this group of patients were treated with VSS. On follow-up angiography, $86 \%$ of stent constructs remained widely patent, whereas $14 \%$ of patients developed SRS and underwent an additional VSS procedure. This study suggests that VSS may be a reasonable alternative treatment for refractory headaches in a certain subset of EDS-HT patients.
In our experience, CTV and MRV are not sufficiently sensitive or specific in the diagnosis of physiologically significant venous obstruction or venous pressure gradients. Additionally, we found that the radiologic or angiographic identification of an anatomical venous stenosis was not reliable for predicting venous pressure gradients. None of the patients in this cohort had any significant complications following the diagnostic angiogram. As such, we believe that diagnostic cerebral angiography and venography is both necessary and safe to define the population which may benefit from VSS. In 74 patients who underwent VSS, technical success with resolution of the pressure gradient was achieved in $100 \%$, with a $4 \%$ significant procedural complication rate. Headaches and cognitive symptoms significantly improved or completely resolved in $77 \%$ of patients. These results support the hypothesis that dural venous sinus outflow abnormalities contribute to the underlying etiology of headache and cognitive symptoms in a subset of EDSHT patients, and that VSS is a safe and effective treatment for appropriately selected patients.

\section{Limitations}

While the results of this study appear promising, they must be interpreted with caution. The study design is retrospective without a control arm. Invasive techniques are often associated with a high placebo response rate, and the clinical course or natural history of untreated EDS-HT is not well delineated. Consequently, in the absence of a control arm, the degree of improvement in subjective symptoms (e.g., headaches, cognitive disturbances) as a result of treatment versus a placebo effect or the natural course of the EDS-HT is unclear. Moreover, this study was conducted at a single institution that served as a quaternary referral center for local, national and international patients with EDS-HT. As such, its results are subject to the selection, referral, and management biases of the treating physician (senior author KCL). Therefore, it is unknown whether these findings are generalizable to all patients with EDSHT. Finally, longer follow-up is needed to assess the durability of the treatment effect observed in our study.

\section{Conclusion}

The preliminary results of this single-arm, retrospective cohort study support venous outflow abnormalities as a contributing factor to headaches and cognitive disturbances in a subset of patients with EDS-HT. Diagnostic cerebral angiography and venography with venous manometry is both necessary and safe to define the population which may benefit from endovascular treatment with VSS. Restoration of venous outflow with VSS appears to have a favorable risk to benefit profile, and therefore, it may represent a minimally invasive treatment option for appropriately selected EDS-HT patients with severe or progressive symptoms that are refractory to medical management. 


\section{References}

1. Henderson FC, Austin C, Benzel E, Bolognese P, Ellenbogen R, et al (2017) Neurological and spinal manifestations of the Ehlers-Danlos syndromes. American journal of medical genetics Part C, Seminars in medical genetics 175(1): 195-211.

2. Tinkle B, Castori M, Berglund B, Cohen H, Grahame R, et al. (2017) Hypermobile Ehlers-Danlos syndrome (a.k.a. Ehlers-Danlos syndrome Type III and Ehlers-Danlos syndrome hypermobility type): Clinical description and natural history. American journal of medical genetics Part C, Seminars in medical genetics 175(1): 48-69.

3. Castori M, Voermans NC (2014) Neurological manifestations of EhlersDanlos syndrome(s): A review. Iranian journal of neurology 13(4): 190208.

4. Higgins N, Pickard J, Lever A (2015) Borderline Intracranial Hypertension Manifesting as Chronic Fatigue Syndrome Treated by Venous Sinus Stenting. Journal of neurological surgery reports 76(2): e244-247.

5. Higgins N, Trivedi R, Greenwood R, Pickard J (2015) Brain Slump Caused by Jugular Venous Stenoses Treated by Stenting: A Hypothesis to Link Spontaneous Intracranial Hypotension with Idiopathic Intracrania Hypertension. Journal of neurological surgery reports 76(1): e188-193.

6. Cabral de Andrade G, Lesczynsky A, Climaco VM, Pereira ER, Marcelino PO, et al. (2017) Cerebral venous sinuses thrombosis in both transverse sinus and torcula: Multistep endovascular treatment and stenting. Interventional neuroradiology 23(1): 84-89.

7. Chan JW (2017) Current concepts and strategies in the diagnosis and management of idiopathic intracranial hypertension in adults. Journal of neurology 264(8): 1622-1633.

8. Xu K, Yu T, Yuan Y, Yu J (2015) Current Status of the Application of Intracranial Venous Sinus Stenting. International journal of medical sciences 12(10): 780-789.

9. Winters HS, Parker G, Halmagyi GM, Mehta A, Atkins T (2015) Delayed relapse in pseudotumor cerebri due to new stenosis after transverse sinus stenting. BMJ case reports bcr2015011896.

10. Qiu MJ, Chen ZC, Song SJ, Mao SY (2017) Dural Venous Sinus Angioplasty and Stenting for Treatment of Idiopathic Intracranial Hypertension. Chinese medical journal 130(7): 879-880.

11. Satti SR, Leishangthem L, Spiotta A, Chaudry MI (2017) Dural venous sinus stenting for medically and surgically refractory idiopathic intracranial hypertension. Interventional neuroradiology 23(2): 186193.

12. Raper DMS, Ding D, Buell TJ, Crowley RW, Starke RM, et al. (2018) Effect of Body Mass Index on Venous Sinus Pressures in Idiopathic Intracranial Hypertension Patients Before and After Endovascular Stenting Neurosurgery 82(4): 555-561.

13. Matloob SA, Toma AK, Thompson SD, Gan CL, Robertson F, et al. (2017) Effect of venous stenting on intracranial pressure in idiopathic intracranial hypertension. Acta Neurochir (Wien) 159(8): 1429-1437.

14. Hui FK, Abruzzo T, Ansari SA (2016) Endovascular Interventions for Idiopathic Intracranial Hypertension and Venous Tinnitus: New Horizons. Neuroimaging clinics of North America 26(2): 289-299.

15. Aguilar Perez M, Martinez Moreno R, Kurre W, Wendl C, Bazner H, et al (2017) Endovascular treatment of idiopathic intracranial hypertension: retrospective analysis of immediate and long-term results in 51 patients. Neuroradiology 59(3): 277-287.

16. Starke RM, Wang T, Ding D, Durst CR, Crowley RW, et al. (2015) Endovascular Treatment of Venous Sinus Stenosis in Idiopathic Intracranial Hypertension: Complications, Neurological Outcomes, and Radiographic Results. The Scientific World Journal 140408.

17. Honarmand AR, Hurley MC, Ansari SA, Alden TD, Kuhn R, et al. (2016) Focal stenosis of the sigmoid sinus causing intracranial venous hypertension: Case report, endovascular management, and review of the literature. Interventional neuroradiology 22(2): 240-245.
18. Raper DM, Buell TJ, Chen CJ, Ding D, Starke RM, et al. (2017) Intracranial venous pressures under conscious sedation and general anesthesia. Journal of neuro interventional surgery $9(10)$.

19. Satti SR, Leishangthem L, Chaudry MI (2015) Meta-Analysis of CSF Diversion Procedures and Dural Venous Sinus Stenting in the Setting of Medically Refractory Idiopathic Intracranial Hypertension. AJNR Am J Neuroradiol 36(10):1899-1904.

20. Gross BA, Albuquerque FC, Moon K, Mc Dougall CG (2016) New frontiers in venous sinus stenting: Illustrative cases. J Clin Neurosci 33: 241-244.

21. Ding D, Chen CJ, Starke RM, Liu KC, Crowley RW (2015) Ophthalmologic course of bilateral abducens nerve palsies after the treatment of idiopathic intracranial hypertension with venous sinus stenting. Neurological sciences 36(12): 2297-2299.

22. Raper DMS, Ding D, Chen CJ, Buell TJ, Crowley RW, et al. (2017) Patency of the vein of Labbe after venous stenting of the transverse and sigmoid sinuses. Journal of neuro interventional surgery 9(6): 587-590.

23. Raper D, Buell TJ, Ding D, Chen CJ, Starke RM, et al. (2018) Pattern of pressure gradient alterations after venous sinus stenting for idiopathic intracranial hypertension predicts stent-adjacent stenosis: A proposed classification system. Journal of neuro interventional surgery 10(4): 391-395.

24. Raper DM, Buell TJ, Ding D, Pomeraniec IJ, Crowley RW, et al. (2018) A pilot study and novel angiographic classification for superior sagittal sinus stenting in patients with non-thrombotic intracranial venous occlusive disease. Journal of neurointerventional surgery 10(1): 74-77.

25. El Mekabaty A, Obuchowski NA, Luciano MG, John S, Chung CY, et al. (2017) Predictors for venous sinus stent retreatment in patients with idiopathic intracranial hypertension. Journal of neuro interventional surgery 9(12): 1228-1232.

26. Boddu S, Dinkin M, Suurna M, Hannsgen K, Bui X, et al. (2016) Resolution of Pulsatile Tinnitus after Venous Sinus Stenting in Patients with Idiopathic Intracranial Hypertension. PloS one 11(10): e0164466.

27. Dinkin MJ, Patsalides A (2017) Venous Sinus Stenting for Idiopathic Intracranial Hypertension: Where Are We Now? Neurol Clin 35(1): 5981.

28. Liu KC, Starke RM, Durst CR, Wang TR, Ding D, et al. (2017) Venous sinus stenting for reduction of intracranial pressure in IIH: a prospective pilot study. J Neurosurg 127(5): 1126-1133.

29. Dinkin MJ, Patsalides A (2017) Venous Sinus Stenting in Idiopathic Intracranial Hypertension: Results of a Prospective Trial. Journal of neuro-ophthalmology 37(2): 113-121.

30. Levitt MR, Albuquerque FC, Gross BA, Moon K, Jadhav AP, et al. (2017) Venous sinus stenting in patients without idiopathic intracranial hypertension. Journal of neuro interventional surgery 9(5): 512-515.

31. Iyer RR, Solomon D, Moghekar A, Goodwin CR, Stewart CM, et al. (2017) Venous sinus stenting in the management of patients with intracranial hypertension manifesting with skull base cerebrospinal fluid leaks. World neurosurgery 106: 103-112.

32. Shazly TA, Jadhav AP, Aghaebrahim A, Ducruet AF, Jankowitz BT, et al. (2018) Venous sinus stenting shortens the duration of medical therapy for increased intracranial pressure secondary to venous sinus stenosis. Journal of neurointerventional surgery 10(3).

33. Ding D, Starke RM, Durst CR, Crowley RW, Liu KC (2014) Venous stenting with concurrent intracranial pressure monitoring for the treatment of pseudotumor cerebri. Neurosurg Focus 37(2): 1.

34. Radvany MG, Solomon D, Nijjar S, Subramanian PS, Miller NR, et al. (2013) Visual and neurological outcomes following endovascular stenting for pseudotumor cerebri associated with transverse sinus stenosis. Journal of neuro-ophthalmology 33(2): 117-122.

35. Lai LT, Danesh Meyer HV, Kaye AH (2014) Visual outcomes and headache following interventions for idiopathic intracranial hypertension. J Clin Neurosci 21(10): 1670-1678. 
ISSN: 2574-1241

DOI: 10.26717/BJSTR.2020.26.004374

Robert Maurer. Biomed J Sci \& Tech Res

(c) $(7)$ This work is licensed under Creative (c) Commons Attribution 4.0 License

Submission Link: https://biomedres.us/submit-manuscript.php

\begin{tabular}{ll} 
BIOMEDICAL & Assets of Publishing with us \\
RESEARCHES & - Global archiving of articles \\
& - Immediate, unrestricted online access \\
\hline
\end{tabular}

